\title{
Microalgae as substrates for fermentative biogas production in a combined biorefinery concept
}

\author{
$3 \quad$ J.H. Mussgnug*, V. Klassen, A. Schlüter, O. Kruse \\ 4 Q1 Bielefeld University, Center for Biotechnology, Universitätsstrasse 27, 33615 Bielefeld, NRW, Germany
}

\section{A R T I C L E I N F O}

\section{Article history:}

Received 15 June 2010

Received in revised form 20 July 2010

Accepted 27 July 2010

Available online $\mathrm{xxx}$

\section{Keywords:}

Bioenergy

Biogas

Biorefinery

Fermentation

Methane

Microalga

\begin{abstract}
A B S T R A C T
Most organic matter can be used for bioenergy generation via anaerobic fermentation. Today, crop plants like maize play the dominant role as substrates for renewable biogas production. In this work we investigated the suitability of six dominant microalgae species (freshwater and saltwater algae and cyanobacteria) as alternative substrates for biogas production. We could demohstrate that the biogas potential is strongly dependent on the species and on the pretreatment. Fermentation of the green alga Chlamydomonas reinhardtii was efficient with a production of $587 \mathrm{ml}( \pm 8.8 \mathrm{SE})$ biogas g volatile solids ${ }^{-1}$ $\left(\mathrm{VS}^{-1}\right)$, whereas fermentation of Scenedesmus obliquus was inefficient with only $287 \mathrm{ml}( \pm 10.1 \mathrm{SE})$ biogas V VS$^{-1}$ being produced. Drying as a pretreatment decreased the amount of biogas production to ca. $80 \%$. The methane content of biogas from microalgae was $7-13 \%$ higher compared to biogas from maize silage. To evaluate integrative biorefinery concepts, hydrogen production in C. reinhardtii prior to anaerobic fermentation of the algae biomass was measured and resulted in an increase of biogas generation to $123 \%$ ( $\pm 3.7 \mathrm{SE}$ ). We conclude that selected algae species can be good substrates for biogas production and that anaerobic fermentation can seriously be considered as final step in future microalgae-based biorefinery concepts.
\end{abstract}

(C) 2010 Published by Elsevier B.V.

\section{Introduction}

The global energy demand keeps rising at a dramatic speed since the beginning of the industrial revolution in the late 18th century. In contrast, easy accessible fossil fuel reserves rapidly decrease which leads to increasing energy prices. For these reasons, one of the major challenges for industrialized countries today is it to ensure the energy supply for the future. Combustion of fossil energy carriers like petrol, natural gas or coal leads to the release of $\mathrm{CO}_{2}$ and therefore to environmental problems which are projected to manifest in problematic climate changes (IPCC, 2007). In recent years, numerous ideas have been considered to develop environmentally more friendly alternatives. The energy sources which are tapped include wind energy, geothermal temperature differences, kinetic energy stored in water (e.g. wave and tidal movements of the oceans or river dams) and the irradiation of the sun. From these, by far the biggest energy source is the solar irradiation. It has been calculated that the energy which reaches the earth's surface equals to around 5600 times the global energy demand today (Schenk et al., 2008). A variety of methods have been developed to harvest this huge energy source, which is technically challenging because of the dis-

Abbreviations: SE, standard error; VS, volatile solids

* Corresponding author. Tel.: +490521 106 12257; fax: +490521 10612290.

E-mail address: jan.mussgnug@uni-bielefeld.de (J.H. Mussgnug). persed and strongly fluctuating nature in which solar irradiation reaches the planet. These methods include photovoltaics, the collection of solar heat and the biological production of plant biomass and subsequent conversion. Biomass can be converted into a number of different products, e.g. into bioethanol, biodiesel or biogas. In recent years it has increasingly become clear that "first generation" biofuels such as ethanol production from plant sugars or biodiesel production from plant lipids have got comparably bad energy balances and therefore most likely can never play a major role in global energy supply, whereas "second generation" biofuels, which convert the whole plant (e.g. biomass-to-liquid or biogas fermentation) offer far greater potentials (IEA, 2010).

In general, the use of plant biomass for energy generation today is problematic because of the competition with food or feed production. This is because most of the plants used for energy generation today (crop plants, sugar cane, sugar beets, canola, etc.) have to be grown on arable land. Low demand alternatives like switchgrass are only beginning to emerge.

Algae have got a number of potential advantages compared to higher plants because of faster growth rates and the possibility of cultivation on non-arable land areas or in lakes or the ocean, therefore attenuating food and feed competition (Rittmann, 2008; Stephens et al., 2010). A promising approach therefore seems to be the use of fast-growing algae species for anaerobic fermentation to produce biogas, which then can substitute natural gas resources. Research on anaerobic fermentation of algae biomass goes back 
${ }_{66}$ Q2 to more than 50 years ago (Goluke and Oswald, 1956). Since then quite a number of research projects have been carried out. The early research efforts peaked in the late 1970th and 1980th as a consequence of the first oil crises. Species under investigation included several macroalgae such as Macrocystis, Gracilaria, Hypnea, Ulva, Laminaria and Sargassum (Chynoweth, 2002). Recently, the identification of microalgal strains with promising characteristics (Eroglu and Melis, 2010), progress in microalgae cultivation (Posten, 2009) and harvesting techniques (Brennan and Owende, 2010) as well as the potential of some strains to produce valuable co-products (Spolaore et al., 2006) has raised the interest to use these organisms for bioenergy generation. In contrast to higher plants and macroalgae, some microalgae like the green microalga Chlamydomonas reinhardtii have the remarkable ability to produce hydrogen via hydrolysis of water during illumination (Kruse et al., 2005b; Melis et al., 2000), which represents an additional environmentally friendly gaseous fuel. This potential has stimulated the research interest in recent years (Doebbe et al., in press, 2007; Hemschemeier et al., 2009; Nguyen et al., 2008; Ruhle et al., 2008; Timmins et al., 2009). Hydrogen generation is a two-phase process with an aerobic and an anaerobic stage, during which the cells undergo major physiological changes. After hydrogen production, algal biomass remains as a waste product. In the context of bioenergy production with microalgae it has been suggested that residual algal biomass should be converted into biogas via anaerobic fermentation (Chisti, 2007; De Schamphelaire and Verstraete, 2009). Although research in the field of microalgae as substrates for biogas production is very limited (Golueke et al., 1957; Hernandez and Cordoba, 1993; Legros et al., 1983; Samson and LeDuy, 1986; Yen and Brune, 2007), recent theoretical calculations (Sialve et al., 2009) indicated their potential.

In this study we determined the potential of six dominant microalgal species as a substrate for biogas production. In addition, we tested the influence of drying as a pre-treatment. The application of microalgae in a two-step biorefinery process (1st step hydrogen production, 2nd step fermentative biogas production) was investigated with the green microalga $C$. reinhardtii.

\section{Materials and methods}

\subsection{Growth and culture conditions}

C. reinhardtii strain cc124 was obtained from the Chlamydomonas Center (Duke University, Durham NC, USA). All other microalgal strains used in this study were obtained from the SAG algae collection (Goettingen University, Germany). Liquid cultures were grown in continuous white light $\left(40 \mu \mathrm{mol} \mathrm{m}^{-2} \mathrm{~s}^{-1}\right)$, TAP medium (Harris, 2009) was used for $C$. reinhardtii, C. kessleri and $E$. gracilis (in the latter case, Thiamin $(0.1 \mathrm{mg} / \mathrm{l})$, Biotin $(0.5 \mu \mathrm{g} / \mathrm{l})$ and vitamin B12 $(0.5 \mu \mathrm{g} / \mathrm{l})$ were added), Spirulina medium (Aiba and Ogawa, 1977) was used for A. platensis, ProF medium (Provasoli et al., 1957) was used for S. obliquus and $2 \mathrm{M} \mathrm{NaCl}$ medium (Pick et al., 1986 ) was used for $D$. salina. Algae cells were harvested by centrifugation $(6 \mathrm{~min}$ at $3.100 \times \mathrm{g}$ ) and the content of organic dry biomass of the pellets was determined by drying at $105^{\circ} \mathrm{C}$ for $24 \mathrm{~h}$. For comparative fermentation tests, fresh or dried cells corresponding to equal organic dry biomass were applied as substrates.

\subsection{Hydrogen production in C. reinhardtii}

Hydrogen production in C. reinhardtii was induced via the sulfur deprivation method established by Melis et al. (2000) as described in detail elsewhere (Doebbe et al., 2007). Briefly, cells were grown in sulfur-containing medium until they reached the early stationary growth phase and then harvested by centrifugation. The cell pellets were washed and re-suspended in sulfur-free medium. The culture was then sealed and incubated in the light $\left(600 \mu \mathrm{mol} \mathrm{m}^{-2} \mathrm{~s}^{-1}\right)$ at room temperature. Under these conditions, photosystem II is progressively inhibited while mitochondrial respiration stays active, leading to anaerobic culture conditions and subsequent hydrogen production approximately $24 \mathrm{~h}$ after cell transfer into sulfur-free medium (Melis et al., 2000). Cells were harvested when hydrogen production had stopped ( $192 \mathrm{~h}$ after the transfer) and the biomass was used for fermentation tests.

\subsection{Anaerobic substrate fermentation and biogas analysis}

Substrate fermentation was conducted in $250 \mathrm{ml}$ batch tests at $38^{\circ} \mathrm{C}$ according to the guideline VDI 4630 of the Verein Deutscher Ingenieure (VDI, 2004). $250 \mathrm{ml}$ biogas batch fermenters were filled with $60 \mathrm{ml}$ sludge from a local sewage plant, cellular material corresponding to $0.5 \mathrm{~g}$ of dried biomass per test was loaded and the fermenter then sealed with a rubber septum. The amount of biogas produced was determined by measurements of the pressure (WAL-BMP-Test system 3150, WAL, Germany) building up in the fermenter head space. Fermenters without addition of substrates were used as negative controls. Biogas composition was determined with an ATEX biogas monitor BM2000 (Ansyco, Germany). The individual biogas production curves were analyzed with the curve fitting software at Zunzun.com to derive the mathematical description of the curves and obtain specific values for each time point. Cell degradation rates were determined by light microscopy (Motic BA310, Motic, China) of fermenter samples and subsequent cell counting.

\section{Results and discussion}

126

127

128

129

130

131

132

133

\subsection{Microalgal biogas production is strongly dependent on the selected strain}

The microalgal species selected for this approach are all common in moderate climate zones and show fast growth rates in the nature and under standard growth condition in the laboratory, therefore they represent a selection of dominant strains. Five eukaryotic microalgal species were selected; four green algae (C. reinhardtii, Dunaliella salina and Scenedesmus obliquus from the class Chlorophyceae and Chlorella kessleri from the class Trebouxiophyceae) and one euglenoid species (Euglena gracilis from the class Euglenoidea) as well as the prokaryotic cyanobacterium Arthrospira platensis (class Cyanophyceae). D. salina and A. platensis are halophilic species; all other species tested are fresh water microalgae.

The suitability of fresh microalgal biomass as substrate for the production of biogas was assessed in anaerobic fermentation batch tests over a period of 32 days (Fig. 1). Equal amounts of biomass (on the basis of dry biomass) were loaded.

As a first important result, the experiments revealed that the biogas quantity produced in the fermenters was strongly dependent on the species. The green freshwater alga $C$. reinhardtii was identified as the most efficient biogas substrate $\left(587 \mathrm{ml} \pm 8.8 \mathrm{SEgVS}^{-1}\right)$, followed by the halophilic green alga $D$. salina $\left(505 \mathrm{ml} \pm 24.8 \mathrm{SEg} \mathrm{VS}^{-1}\right)$. Compared to the standard substrate control Z. mays silage ( $\left.653 \mathrm{ml} \pm 37.7 \mathrm{SEg} \mathrm{VS}^{-1}\right)$, these two algae produced $90 \%$ (C. reinhardtii) and $77 \%$ (D. salina) of the biogas amount (Fig. 1), respectively. Application of biomass from the prokaryotic cyanobacterium $A$. platensis or the euglenoid alga $E$. gracilis as substrates also resulted in comparably high biogas production (both $74 \%$ of the control) with $481 \mathrm{ml} \pm 13.8 \mathrm{SE} \mathrm{g} \mathrm{VS}^{-1}$ for A. platensis and $485 \mathrm{ml} \pm 3 \mathrm{SE} \mathrm{g} \mathrm{VS}^{-1}$ for E. gracilis, respectively. Biogas production from C. kessleri was significantly lower (335 $\mathrm{ml} \pm 7.8$ 
Table 1

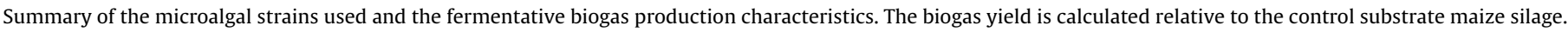

\begin{tabular}{|c|c|c|c|c|}
\hline (P)ro- or (E)ukaryotic species & Fresh $(F)$ or salt $(S)$ water & Biogas production $\left(\mathrm{mlg} \mathrm{VS}^{-1}\right)$ & $\mathrm{CH}_{4}$ content & Methane yield (\% control) \\
\hline Arthrospira platensis $(\mathrm{P})$ & $\mathrm{S}$ & $481 \pm 13.8$ & $61 \%$ & $83 \%$ \\
\hline Chlamydomonas reinhardtii (E) & $\mathrm{F}$ & $587 \pm 8.8$ & $66 \%$ & $111 \%$ \\
\hline Chlorella kessleri (E) & $\mathrm{F}$ & $335 \pm 7.8$ & $65 \%$ & $62 \%$ \\
\hline Dunaliella salina (E) & $\mathrm{S}$ & $505 \pm 24.8$ & $64 \%$ & $93 \%$ \\
\hline Euglena gracilis $(\mathrm{E})$ & $\mathrm{F}$ & $485 \pm 3$ & $67 \%$ & $93 \%$ \\
\hline Scenedesmus obliquus (E) & $\mathrm{F}$ & $287 \pm 10.1$ & $62 \%$ & $51 \%$ \\
\hline Zea mays (E) & $\mathrm{F}$ & $653 \pm 37.7$ & $54 \%$ & $100 \%$ \\
\hline
\end{tabular}

SEgVS${ }^{-1}, 51 \%$ of the control), but still superior compared to $S$. obliquus ( $287 \mathrm{ml} \pm 10.1 \mathrm{SE} \mathrm{g} \mathrm{VS}^{-1}, 44 \%$ of the control), which represented the worst strain in terms of anaerobic degradability (Fig. 1). These results clearly showed that the suitability of microalgae for anaerobic fermentation and biogas production cannot be predicted from the classification of the organism and indicates that the biogas potential is strain-specific and always needs to be tested individually.

The main components of biogas are methane and carbon dioxide. The variable, relative amount of methane determines the biogas quality and depends on the substrate and the fermentation conditions (Sialve et al., 2009). All microalgae tested showed higher specific methane contents (ranging from 61\% to 67\%) compared to the standard substrate maize silage (54\%; Table 1 ). This result is in good agreement with theoretical considerations and previous studies (Sialve et al., 2009) and indicates the potential of algal substrates for superior biogas quality compared to traditionally used higher plants. Taking this higher specific methane content into account, fresh biomass from $C$. reinhardtii produced $11 \%$ more pure methane when compared to fresh biomass derived from $Z$. mays (Table 1). Hydrogen sulfide $\left(\mathrm{H}_{2} \mathrm{~S}\right)$ is commonly found in biogas produced from organic substrates in small amounts. Because of its toxic and corrosive nature, low amounts of $\mathrm{H}_{2} \mathrm{~S}$ are desirable. Although we did not determine $\mathrm{H}_{2} \mathrm{~S}$ levels within the biogas from microalgal substrates, it has been suggested that the $\mathrm{H}_{2} \mathrm{~S}$ levels should be low because of the comparably low amount of sulfurated amino acids in microalgae (Sialve et al., 2009). However, future studies on the combustion and purification characteristics of biogas from microalgae will be necessary to exclude unknown and potentially detrimental aspects before large scale application can be considered.

\subsection{The biogas potential correlates with the level of cellular disintegration}

The degree of cell degradation is crucial for the conversion efficiency from algae biomass to biogas. Consequently, we inves-

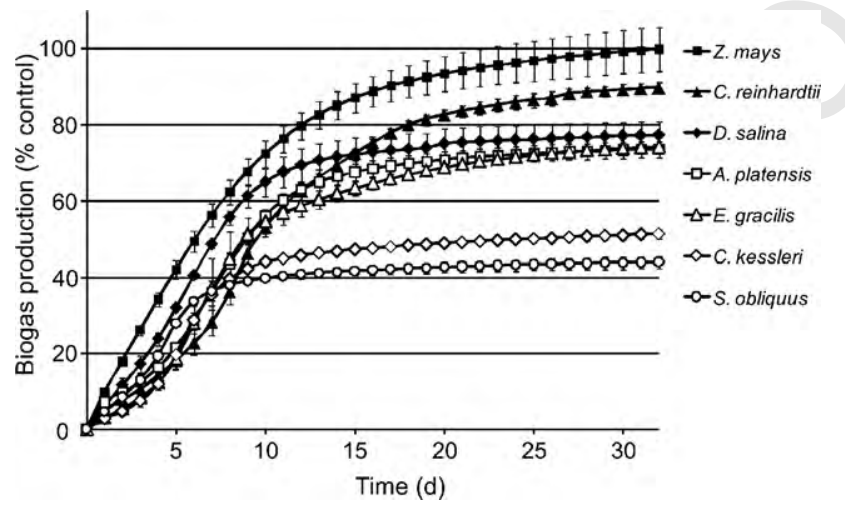

Fig. 1. Net biogas production of six microalgal strains. Fresh algal biomass was subjected to fermentation on the basis of equal dry biomass content. Maize silage was used as a positive control. The gas amount produced by fermenters without substrate addition (negative control) was subtracted. Error bars represent standard errors. tigated the cellular disintegration of the algal substrate by light microscopy. Fresh algal substrate was centrifuged and added to batch fermenters and the kinetics of cell disintegration determined by cell counting. Interestingly, the salt water species disintegrated very fast after addition to the fermenter sludge (A. platensis and $D$. salina; Fig. 2).

Here, very few (Fig. 3B, arrow) or no (Fig. 3C) indigestible residues of the cells were detected via light microscopy. In contrast, all fresh water microalgae generally showed slower decomposition rates (Fig. 2) with some indigestible residues remaining (Fig. 3A, D-F).

In general, the decrease of the cell degradation correlated well with the amount of biogas produced. The species with a high degree of decomposition and low amount of indigestible residues (C. reinhardtii, D. salina, A. platensis and E. gracilis) showed higher amounts of biogas production compared to the species with a lower degree of decomposition and higher amount of indigestible residues ( $C$. kessleri and S. obliquus) (Figs. 1 and 2; Table 1). Consequently, our results indicate that without a pretreatment, the accessibility to cell disintegration is most likely a major factor for the efficiency of fermentative biogas production.

It should be noted that all easy degradable species investigated in this study have got no cell wall (D. salina (Sheffer et al., 1986)) or a protein-based cell wall containing no cellulose or hemicellulose (C. reinhardtii (Miller et al., 1972), A. platensis (van Eykelenburg et al., 1980), E. gracilis (Nakano et al., 1987)). In contrast, C. kessleri and S. obliquus are characterized by having carbohydrate-based cell walls containing hemicellulose (Takeda, 1991, 1996). The cell wall of $S$. obliquus has been described as particular rigid because it contains a sporopollenin-like biopolymer (Burczyk and Dworzanski, 1988) which explains why no cell degradation of this strain could be detected (Figs. 2 and 3F). It is worth noting that we were able to detect intact Scenedesmus cells (as assessed from microscopic images) more than six months after the transfer into the fermenter (data not shown). During this time, the fermenter was kept in darkness, therefore preventing photosynthetic reactions. It has been

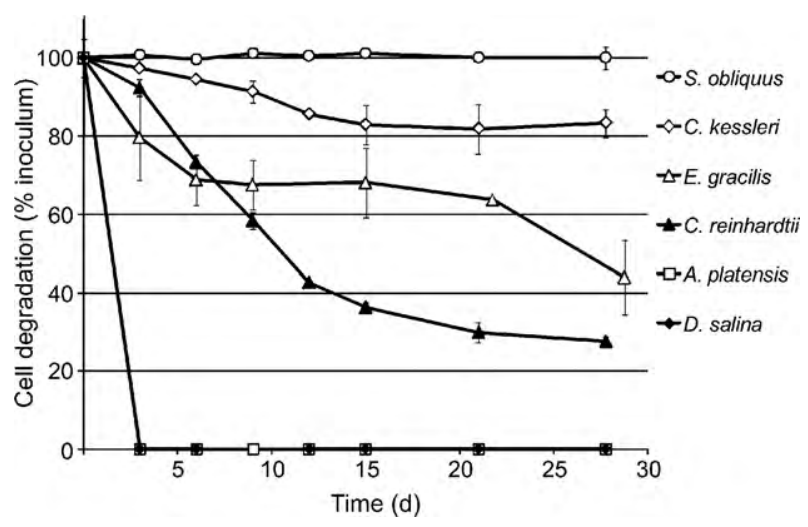

Fig. 2. Kinetics of microalgal cell disintegration in the fermenter. Fresh microalgal biomass was added to the fermenter sludge and the cell number was monitored by light microscopy. Error bars represent standard errors. 


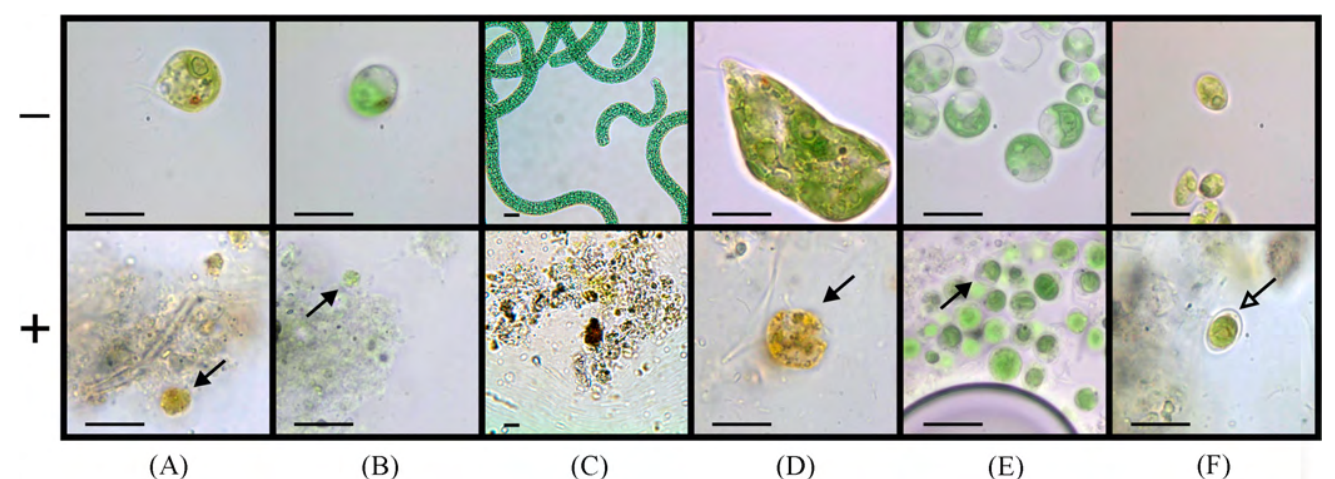

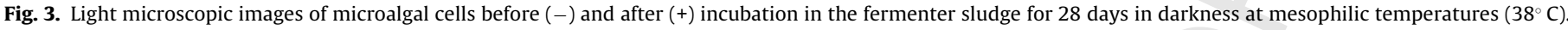
(A) C. reinhardtii; (B) D. salina; (C) A. platensis; (D) E. gracilis; (E) C. kessleri; (F) S. obliquus. Scale bars represent $10 \mu \mathrm{m}$.

shown that Scenedesmus can utilize a wide variety of sugars (e.g. glucose, fructose or galactose) and organic acids (e.g. acetate or pyruvate) for heterotrophic growth (Dvorakov, 1966). Therefore our results indicate that the cells, protected from bacterial disintegration, were indeed able to survive by uptake of fixed carbon compounds from the fermenter sludge. However, we did not see any evidence for algal cell growth or division within the fermenter. Interestingly, a comparably low, but significant biogas production was measured with $S$. obliquus substrate despite the fact that the cell number remained constant. A possible explanation for the biogas production could be that to a certain extent, dead/broken cells originating from the cell cultivation were transferred to the fermenter and, in contrast to the living cells, served as substrate for biogas production. Another explanation could be that the surviving Scenedesmus cells actively promoted degradation of organic compounds present in the fermenter sludge, which were not accessible to the bacterial community.

In conclusion, our data indicate that the presence and composition of the cell wall is the main reason for the differences observed in the cell disintegration characteristics and subsequent biogas production. In terms of biogas production efficiency, strains with no cell wall or a protein-based cell wall should be preferred because disruptive, energy consuming pretreatments can be avoided. However, we cannot exclude the possibility that even microalgae without a rigid cell wall could be bad substrates for fermentative biogas production. This is because it is likely that some microalgae will produce compounds which exert detrimental effects on the bacterial biocenosis of the fermenter (Klocke et al., 2007; Schlüter et al., 2008), e.g. by inhibition of the methanogenic archaea. This could explain why $D$. salina and $A$. platensis substrates, although rapidly and completely degraded, resulted in less biogas production than the $C$. reinhardtii substrate (Figs. 1 and 2).

\subsection{Drying as a pretreatment decreases the fermentative potential of the substrates}

Microalgae are grown in liquid medium for mass cultivation and the dry matter content usually is below $15 \mathrm{~g} / \mathrm{l}$ culture, although up to $84 \mathrm{~g} / \mathrm{l}$ have been reported (Hu et al., 1998). Efficient biogas production will therefore require a concentration step, e.g. by filtration or centrifugation. Depending on the concentration method, the fresh algal biomass still contains a high degree of water, e.g. in our case a typical Chlamydomonas pellet after centrifugation contained ca. $6 \%$ VS and 94\% water. For transportation and storage it could be desirable to use dry algal biomass instead of algal biomass concentrate. We therefore tested the effect of drying of the substrate on biogas fermentation. As can be seen in Fig. 4, drying of the biomass resulted in a general decrease of around $20 \%$ of the biogas production potential.
This was true for the control, Z. mays $(-21 \pm 2.4 \%)$ and also for the two algal cell lines tested, $C$. kessleri $(-23 \pm 2.8 \%)$ and $C$. reinhardtii $(-20 \pm 2.7 \%)$. The most likely reasons for the decreased biogas production are the loss of volatile organic compounds of high fermentation potential and/or a decreased accessibility of the dried organic compounds for the bacterial biocenosis within the fermenter sludge. In any case, our results demonstrate that drying is detrimental in terms of biogas production and should be avoided. Since drying of the biomass would require energy of some sort it can be concluded that the most energy efficient way of using algal biomass for fermentation is to use fresh biomass and avoid transportation if possible. This could be achieved by building and operating the algal production facility in close proximity to the biogas fermentation plant.

\subsection{Hydrogen production in C. reinhardtii leads to higher subsequent biogas production levels}

Industrial large scale growth of microalgae still is in its infancy and the algae biomass therefore rather expensive. The general consensus today seems to be that biorefinery concepts have to be adopted to achieve economical feasibility, where algae are used to produce a valuable substance prior to being subjected to fermentation (Chisti, 2007; Schenk et al., 2008; Spolaore et al., 2006; Stephens et al., 2010). The green microalga $C$. reinhardtii has the ability to produce biosolar hydrogen $\left(\mathrm{H}_{2}\right)$ under anaerobic conditions (Doebbe et al., 2007; Hemschemeier et al., 2009; Kruse

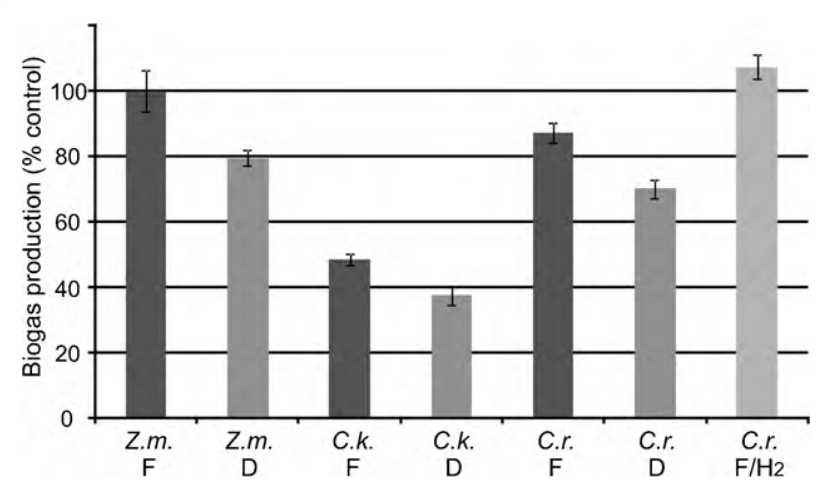

Fig. 4. The influence of drying and hydrogen production as pretreatments on the biogas production potential of the substrate. Fresh biomass (F) was directly used for fermentation or dried (D) at $105^{\circ} \mathrm{C}$ for $24 \mathrm{~h}$ prior to fermentation. In addition, C. reinhardtii cells were subjected to hydrogen production and fresh biomass subsequently used for fermentation $\left(\mathrm{F} / \mathrm{H}_{2}\right)$. Equal amounts on the basis of dry biomass were loaded. The gas amount produced by fermenters without substrate addition (negative control) was subtracted. Z.m. Zea mays; C.k., Chlorella kessleri; C.r. Chlamydomonas reinhardtii. Error bars represent standard errors. 


\section{Q3 Uncited reference}

\section{Conclusions}

$$
\text { Takeda (1996). }
$$
porting our work. et al., 2005a; Melis et al., 2000), which has the potential to be a first step within an energetic biorefinery concept. Similar to biogas production, harvesting of gaseous $\mathrm{H}_{2}$ as a product does not depend on energy consuming downstream processes. In addition, the $\mathrm{H}_{2}$ production is driven by photosynthesis, therefore directly converting sun light energy into $\mathrm{H}_{2}$. To evaluate the viability of the outlined biorefinery concept, we investigated if biosolar $\mathrm{H}_{2}$ production prior to fermentation of the residual biomass has an influence on the fermentative potential of the substrate. Most interestingly we found that the biogas yield increased to $123 \%( \pm 3.7)$ compared to fresh algal biomass when biomass after the hydrogen production cycle was used (Fig. 4). As has been shown previously, storage compounds with high fermentative potential like starch and lipids strongly increase within the cells as a response to the induction of the hydrogen production cycle (Doebbe et al., in press; Timmins et al., 2009). The increased content of easy degradable storage compounds is a good explanation why the residual biomass after hydrogen production is a better substrate for biogas production compared to fresh biomass. It should also be noted that hydrogen production experimentally is induced by sulfur starvation, therefore decreasing the risk of $\mathrm{H}_{2} \mathrm{~S}$ accumulation in the biogas.

In this work we investigated the potential of six dominant microalgal strain for biogas production and evaluated drying and hydrogen production as pretreatments prior to the anaerobic fermentation. As a general conclusion, our results indicate that certain microalgal species can be good substrates for anaerobic fermentation, resulting in the production of biogas with relatively high methane content and in this respect have the potential to replace higher plant material like maize which is generally used today. However, the biogas production potential is strongly dependent on the algal strain used. From our data we cannot draw the simple conclusion that certain algal genera are more suitable than others. In our study, the best and the worst biogas substrates actually were phylogenetically fairly closely related (both belonging to the class Chlorophyceae). Our results therefore indicate that strain specific factors like cell wall composition or the production of compounds directly (e.g. bacteriostatic or bactericidal compounds) or indirectly (e.g. high relative protein content leading to the release of toxic, free ammonia (Sialve et al., 2009)) detrimental to the bacterial community in the fermenter strongly influence the suitability of the individual strains. If the inhibiting factors are identified, pretreatment strategies (e.g. physical disruption of the cell wall, lowering the relative protein content by induction of lipid production by nutrient starvation) could be applied to alleviate the inhibitory effects. Algal substrates should be concentrated, but complete drying at high temperatures should be avoided since the biogas potential decreases significantly. In contrast, hydrogen production in C. reinhardtii was shown to increase the biogas production potential which leads us to the conclusion that biorefinery concepts in some cases can indeed result in unexpected synergistic effects.

\section{Acknowledgements}

We would like to acknowledge EU-FP7 collaborative project SUNBIOPATH (03SF0361G) and the BMBF collaborative project HydrMicPro (\#245070) for funding and the Consortium Bioenergy OWL with the Stadtwerke Bielefeld and Biogas Nord GmbH for sup-

\section{References}

Aiba, S., Ogawa, T., 1977. Assessment of growth yield of a blue-green alga, Spirulina platensis, in axenic and continuous culture. Journal of General Microbiology 102, 179-182.

Brennan, L, Owende, P. 2010. Biofuels from microalgae-A review of technologies for production, processing, and extractions of biofuels and co-products. Renewable and Sustainable Energy Reviews 14, 557-577.

Burczyk, J., Dworzanski, J., 1988. Comparison of sporopollenin like algal resistant polymer from cell-wall of Botryococcus, Scenedesmus and Lycopodium clavatum by GC pyrolysis. Phytochemistry 27, 2151-2153.

Chisti, Y., 2007. Biodiesel from microalgae. Biotechnology Advances 25, 294-306.

Chynoweth, D., 2002. Review of Biomethane from Marine Biomass. http://www.abe.ufl.edu/ chyn/download/Publications_DC/Reports/marinefinal_FT.p

De Schamphelaire, L., Verstraete, W., 2009. Revival of the biological sunlight to biogas energy conversion system. Biotechnology and Bioengineering 103, 296-304.

Doebbe, A., Keck, M., La Russa, M., Mussgnug, J.H., Hankamer, B., Tekçe, E., Niehaus, K., Kruse, O., in press. The interplay of proton, electron and metabolite supply for photosynthetic $\mathrm{H}_{2}$ production in $C$. reinhardtii. Journal of Biological Chemistry.

Doebbe, A., Rupprecht, J., Beckmann, J., Mussgnug, J.H., Hallmann, A., Hankamer, B. Kruse, O., 2007. Functional integration of the HUP1 hexose symporter gene into the genome of C-reinhardtii: impacts on biological H2 production. Journal of Biotechnology 131, 27-33.

Dvorakov, J., 1966. Utilization of organic substrates during mixotrophic and heterotrophic cultivation of algae. Biologia Plantarum 8, 354-361.

Eroglu, E., Melis, A., 2010. Extracellular terpenoid hydrocarbon extraction and quantitation from the green microalgae Botryococcus braunii var. Showa. Bioresource Technology 101, 2359-2366.

Golueke, C.G., Oswald, W.J., Gotaas, H.B., 1957. Anaerobic digestion of algae. Applied Microbiology 5, 47-55.

Harris, E.H., 2009. The Chlamydomonas Sourcebook. Elsevier, Academic Press.

Hemschemeier, A., Melis, A., Happe, T., 2009. Analytical approaches to photobiological hydrogen production in unicellular green algae. Photosynthesis Research $102,523-540$.

Hernandez, E.P.S., Cordoba, L.T., 1993. Anaerobic digestion of chlorella vulgaris for energy production. Resources Conservation and Recycling 9, 127-132.

Hu, Q., Kurano, N., Kawachi, M., Iwasaki, I., Miyachi, S., 1998. Ultrahigh cell density culture of a marine green alga Chlorococcum littorale in a flat-plate photobioreactor. Applied Microbiology and Biotechnology 49, 655-662.

IEA, 2010. Sustainable Production of Second-Generation Biofuels (Report) http://www.iea.org/papers/2010/second generation biofuels.pdf.

IPCC, 2007. Intergovernmental panel on climate change: fourth assessment report (AR4), http://www.ipcc.ch/pdf/assessment-report/ar4/syr/ar4_syr.pdf.

Klocke, M., Mahnert, P., Mundt, K., Souidi, K., Linke, B., 2007. Microbial community analysis of a biogas-producing completely stirred tank reactor fed continuously with fodder beet silage as mono-substrate. Systematic and Applied Microbiology 30, 139-151.

Kruse, O., Rupprecht, J., Bader, K.P., Thomas-Hall, S., Schenk, P.M., Finazzi, G., Hankamer, B., 2005a. Improved photobiological H2 production in engineered green algal cells. Journal of Biological Chemistry 280, 34170-34177.

Kruse, O., Rupprecht, J., Mussgnug, J.H., Dismukes, G.C., Hankamer, B., 2005b. Photosynthesis: a blueprint for solar energy capture and biohydrogen production technologies. Photochemical and Photobiological Sciences 4, 957-970.

Legros, A., Marzano, C.M.A.D., Naveau, H.P., Nyns, E.J., 1983. Fermentation profiles in bioconversions. Biotechnology Letters $5,7-12$.

Melis, A., Zhang, L.P., Forestier, M., Ghirardi, M.L., Seibert, M., 2000. Sustained photobiological hydrogen gas production upon reversible inactivation of oxygen evolution in the green alga Chlamydomonas reinhardtii. Plant Physiology 122, 127-135.

Miller, D.H., Miller, M., Lamport, D.T.A., 1972. Hydroxyproline heterooligosaccharides in Chlamydomonas. Science 176, 918-920.

Nakano, Y., Urade, Y., Urade, R., Kitaoka, S., 1987. Isolation, purification and characterization of the pellicle of Euglena gracilis z. Journal of Biochemistry 102, 1053-1063.

Nguyen, A.V, Thomas-Hall, S.R., Malnoe, A., Timmins, M., Mussgnug, J.H., Rupprecht J., Kruse, O., Hankamer, B., Schenk, P.M., 2008. Transcriptome for photobiological hydrogen production induced by sulfur deprivation in the green alga Chlamydomonas reinhardtii. Eukaryotic Cell 7, 1965-1979.

Pick, U., Karni, L., Avron, M., 1986. Determination of ion content and ion fluxes in the halotolerant alga Dunaliella salina. Plant Physiology 81, 92-96.

Posten, C., 2009. Design principles of photo-bioreactors for cultivation of microalgae. Engineering in Life Sciences 9, 165-177.

Provasoli, L., Mclaughlin, J.J.A., Droop, M.R., 1957. The development of artificial media for marine algae. Archiv fuer Mikrobiologie 25, 392-428.

Rittmann, B.E., 2008. Opportunities for renewable bioenergy using microorganisms Biotechnology and Bioengineering 100, 203-212.

Ruhle, T., Hemschemeier, A., Melis, A., Happe, T., 2008. A novel screening protocol for the isolation of hydrogen producing Chlamydomonas reinhardtii strains. Bmc Plant Biology 8, 107.

Samson, R., LeDuy, A., 1986. Detailed study of anaerobic digestion of Spirulina maxima algal biomass. Biotechnology and Bioengineering 28, 1014-1023.

Schenk, P.M., Thomas-Hall, S.R., Stephens, E., Marx, U.C., Mussgnug, J.H., Posten, C., Kruse, O., Hankamer, B., 2008. Second generation biofuels: high-efficiency microalgae for biodiesel production. BioEnergy Research 1, 20-43.

Schlüter, A., Bekel, T., Diaz, N.N., Dondrup, M., Eichenlaub, R., Gartemann, K.H., Krahn, I., Krause, L., Kromeke, H., Kruse, O., Mussgnug, J.H., Neuweger, H., Niehaus, K.,

\section{7}

388 
Puhler, A., Runte, KJ., Szczepanowski, R., Tauch, A., Tilker, A., Viehover, P., Goesmann, A., 2008. The metagenome of a biogas-producing microbial community of a production-scale biogas plant fermenter analysed by the 454-pyrosequencing technology. Journal of Biotechnology 136, 77-90.

Sheffer, M., Fried, A., Gottlieb, H.E., Tietz, A., Avron, M., 1986. Lipid composition of the plasma-membrane of the halotolerant alga, Dunaliella salina. Biochimica Et Biophysica Acta 857, 165-172.

Sialve, B., Bernet, N., Bernard, O., 2009. Anaerobic digestion of microalgae as a necessary step to make microalgal biodiesel sustainable. Biotechnology Advances 27, 409-416.

Spolaore, P., Joannis-Cassan, C., Duran, E., Isambert, A., 2006. Commercial applications of microalgae. Journal of Bioscience and Bioengineering 101, 87-96.

Stephens, E., Ross, I.L., King, Z., Mussgnug, J.H., Kruse, O., Posten, C., Borowitzka, M.A., Hankamer, B., 2010. An economic and technical evaluation of microalgal biofuels. Nature Biotechnology 28, 126-128.
Takeda, H., 1991. Sugar composition of the cell wall and the taxonomy of Chlorella (Chlorophyceae). Journal of Phycology 27, 224-232.

Takeda, H., 1996. Cell wall sugars of some Scenedesmus species. Phytochemistry 42, 673-675.

Timmins, M., Zhou, W.X., Rupprecht, J., Lim, L., Thomas-Hall, S.R., Doebbe, A., Kruse, O., Hankamer, B., Marx, U.C., Smith, S.M., Schenk, P.M., 2009. The metabolome of Chlamydomonas reinhardtii following induction of anaerobic $\mathrm{H} 2$ production by sulfur depletion. Journal of Biological Chemistry 284, 35996-135996.

van Eykelenburg, C., Fuchs, A., Schmidt, G.H., 1980. Some theoretical considerations on the in vitro shape of the cross-walls in Spirulina spp. Journal of Theoretical Biology 82, 271-282.

VDI, 2004. Fermentation of organic compounds. Verein Deutscher Ingenieure, VDIHandbuch Energietechnik.

Yen, H.W., Brune, D.E., 2007. Anaerobic co-digestion of algal sludge and waste paper to produce methane. Bioresource Technology 98, 130-134. 